\title{
Wet mount microscopy reflects functional vaginal lactobacillary flora better than Gram stain
}

\author{
Gilbert G G Donders, Annie Vereecken, Alfons Dekeersmaecker, Ben Van Bulck, \\ Bernard Spitz
}

\begin{abstract}
Aim-The status of vaginal lactobacillary flora, an indicator of possible genital infection and pregnancy complications, can be assessed on wet mount or Gram stained specimens. The former is quick, the latter more routine. The accuracy of the two preparative techniques to detect normal vaginal lactobacillary microflora was compared for 646 patients. The effect of delay in transport medium before Gram staining was also investigated.

Methods-Patients presented with infectious vaginitis or for a routine prenatal visit. After placement of a speculum, duplicate smears were taken from the upper vaginal vault and examined fresh or after Gram staining. Lactobacillary grades from both methods were compared with lactate concentration in vaginal rinses. In a subgroup of 238 patients, Gram staining was performed both on fresh smears and those that had been transported in Stuart's growth medium.

Results-Higher lactobacillary grades (more disrupted flora) were diagnosed 2.9 times more frequently on Gram stained specimens than on wet mounts $(p<$ 0.0001 ), a difference even more pronounced after transport in Stuart's medium (relative risk, 4.2; $p<0.0001)$. Lactobacillary grades assessed on wet mounts correlated better with vaginal lactate concentration than those assessed on Gram stains.

Conclusions-Easier recognition of lactobacillary morphotypes on wet mounts than on Gram stains might result from the loss of lactobacilli by the process of fixation or Gram staining. Wet mount microscopy of vaginal smears for assessment of lactobacillary grades, rather than Gram staining, is strongly recommended. (f Clin Pathol 2000;53:308-313)
\end{abstract}

Keywords: Gram stain; vaginal smears; wet mounts; lactobacillary flora

The absence of vaginal lactobacilli has been recognised as a risk factor for genital infections and complications of pregnancy since the end of the 19 th century. ${ }^{12}$ Later studies have used lactobacillary grading (LBG), the recognition of clue cells, and modern bacterial culture techniques to predict associations with genital infectious disease ${ }^{3-6}$ and impaired outcome of pregnancy. ${ }^{5-7}$ Although lactobacillary grading would be a simple and cheap screening technique, there are no data available on which technique should be used for visualisation of the lactobacillary morphotypes. Wet mounting has the advantage that it can be performed immediately and therefore allows immediate preventive, diagnostic, or therapeutic action where indicated. In routine settings, Gram staining is laboratory based and usually performed on the swab used for bacterial and candida culture, which is stored in Stuart's transport medium.

However, the Gram stain and the transport process might alter the lactobacillary flora. ${ }^{8}$ Papanicolaou stained (Pap) smears are performed routinely in some settings and can also be used successfully as screening tools for lactobacillary grading, ${ }^{5}$ but the influence of the staining process on the LBG is not known. Furthermore, the delay in obtaining the results of both Gram stained and Pap specimens makes immediate action impossible, thereby challenging their power for use in mass screening - for example, during pregnancy.

Gram stains, Pap smears, and rehydrated dried wet mounts have all been used for the diagnosis of bacterial vaginosis by the detection of bacterial morphotypes and clue cells. ${ }^{9-11}$ Increasingly, for many authors and reviewers the difference between disturbed lactobacillary flora (LBG III) and bacterial vaginosis has tended to become vague or non-existent. However, this should not be the case, because up to $40 \%$ of patients harbouring abnormal LBG do not fit the diagnostic criteria of bacterial vaginosis according to Amsel et al. ${ }^{12}$

Furthermore, many infectious agents not part of bacterial vaginosis, such as Trichomonas vaginalis, Neisseria gonorrhoeae, Chlamydia trachomatis, Treponema pallidum, and many aerobic facultative enteric pathogens in the vagina, are related to the disturbed lactobacillary flora. ${ }^{56}$ In addition, there is often increased vaginal leucocytosis ( $>10$ leucocytes/epithelial cell), which typically is absent in uncomplicated bacterial vaginosis.

Recently, we compared the accuracy of LBG screening by wet mount with that using Gram stained specimens in a small study and found a higher false positive rate in Gram stained specimens than in wet mounts. ${ }^{8}$ This finding was even more pronounced when the specimen was transported in Stuart's growth medium before being Gram stained. However, although the wet mount and Gram stain methods each have particular advantages and disadvantages, we had no "gold standard" against which to compare the techniques.

The culture of lactobacilli, even on Rogosa medium, does not accurately reflect the amount of functional lactobacilli present, and neither does it provide information on the ratio of lactobacilli to other microbial flora present. In our
Accepted for publication 14 July 1999 
present study we have used vaginal lactate concentration as the gold standard estimate of lactobacillary function, against which the techniques of wet mounting and Gram staining could be compared with one another for their suitability for use in lactobacillary grading. Lactate production by lactobacilli is well known and thought to be specific, because no other vaginal pathogen is known to produce appreciable amounts of lactate. ${ }^{13}$ Lactate production, together with peroxidase activity, are believed to be the key factors in the production and maintenance of vaginal acidity and resistance to bacterial intruders. ${ }^{14}$ To adjust for the possible influence of bacterial vaginosis in this study, we re-analysed the data after excluding all patients with a clinical diagnosis of bacterial vaginosis.

\section{Materials and methods}

SUBJECTS AND SPECIMEN SAMPLING

From January 1993 to July 1995, 646 consecutive patients presenting for routine check up or for presumed genital infection underwent a standardised vaginal speculum examination. An unmoistened speculum was inserted before any other vaginal examination was performed. Vaginal fluid was taken from the posterior vaginal vault with a wooden Ayre's spatula, and spread on to two separate glass slides. On one glass slide, a droplet of $0.9 \% \mathrm{NaCl}$ in water was applied and covered with a glass coverslip for
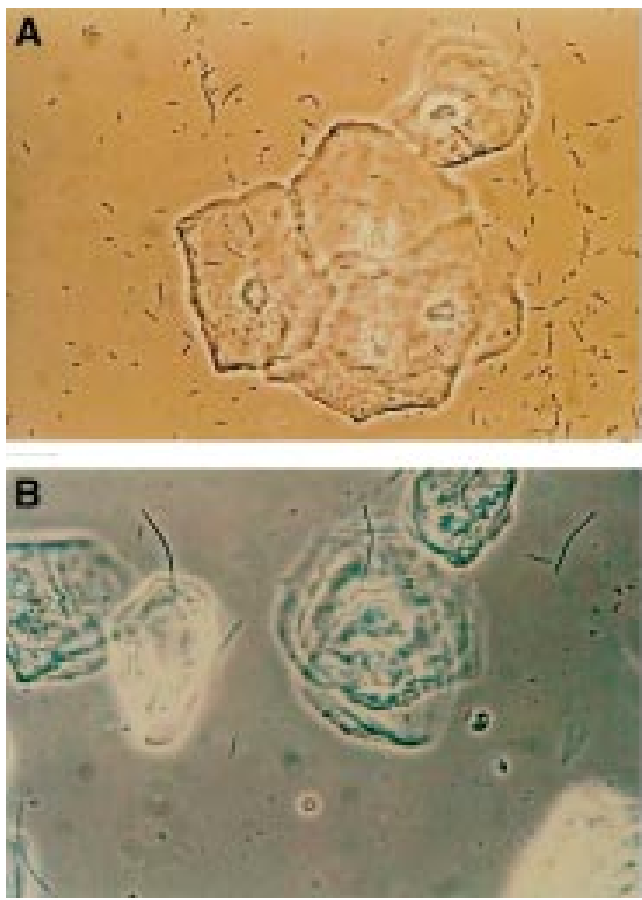

immediate microscopic evaluation. The other glass slide was air dried for later Gram staining. Then, a cotton tipped swab was taken from the posterior vault and immediately placed in Amies's modified Stuart's medium.

In all pregnant patients and in other patients presenting for the first time, an extra slide with vaginal fluid for fresh Gram staining was prepared. From the subgroup of 183 pregnant women, related data have been published elsewhere. $^{8}$

The swab and the air dried glass slide were transported to the laboratory for Gram staining within a maximum of six hours. The swab, which had been stored in Amies's modified Stuart's medium at room temperature for three to six hours, was rolled over a glass slide, fixed in pure alcohol, and stained according to Gram's method. The air dried glass slide was stained at the same time and in the same manner.

\section{GRADING OF THE LACTOBACILLARY}

MORPHOTYPES

All slides were evaluated for lactobacillary grade by one trained technician who was blinded to the origin of the slides and to the results of the wet mount. Wet mounts and Gram stained slides were classified according to a modification of Schröder's original classification (fig 1). Normal, LBG grade I flora correspond predominantly to lactobacillary
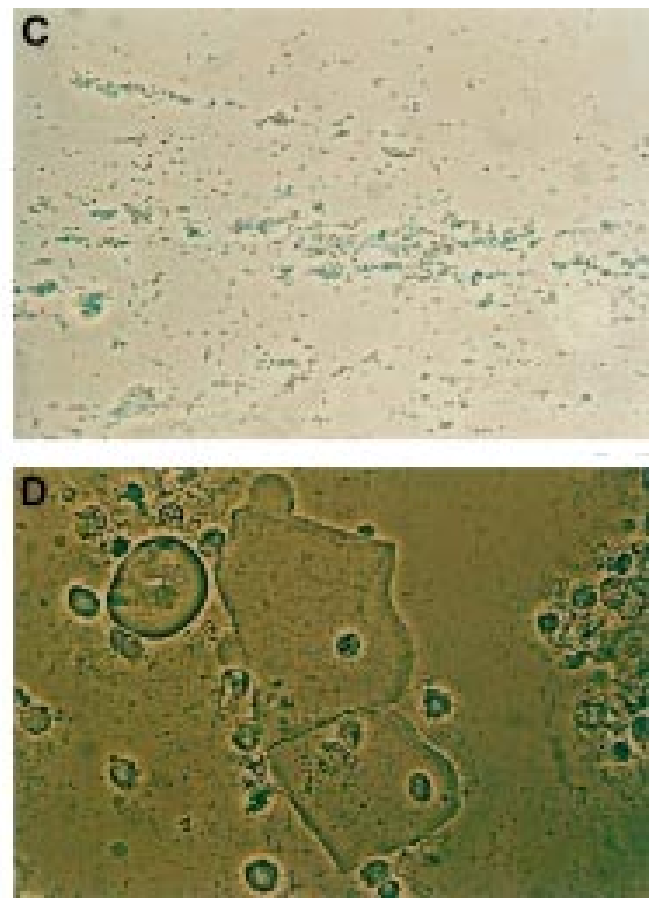

Figure 1 (A) Lactobacillary flora grade I (LBG I) shows numerous lactobacillary morphotypes that are evenly spread and differ in size. No other bacteria are prominent. LGB I corresponds to normal, resistant vaginal flora. (B) Lactobacillary flora grade IIa (LBG IIa) shows lactobacillary morphotypes that are still very abundant, but mixed with other flora. Although slightly more pathogenic bacteria might be present, this flora type may still be seen as normal. (C) Lactobacillary flora grade IIb (LBG IIb) shows overgrowth of other, mostly coccoid, bacteria, but limited numbers of lactobacillary morphotypes are still present. LGB IIb can be seen as a transitory stage between normal and abnormal vaginal flora. Hence, more pathogens than in the former two categories are found in this group, and leucocytosis is often more pronounced. (D) Lactobacillary flora grade III (LBG III) shows coccoid or staphoid bacteria, with no normal looking lactobacillary morphotypes present. This is a gross distortion of the normal flora and leads to the further diagnosis of a sexually transmitted disease (for example, gonorrhoea, Trichomonas vaginalis infection, chlamydia, bacterial vaginosis, or aerobic vaginitis, with or without accompanying cervicitis (desquamative vaginitis)). The specimen in (D) is an example of the latter: the lactobacilli are completely replaced by coccoid bacteria, some of them creating chain like formations (visible on the upper left corner of the lower epithelial cell). Numerous leucocytes are present, and are responsible for an inflammatory, red vagina, and yellow, sticky discharge. Finally, the undifferentiated parabasal epithelial cells (upper left corner) are typically prominent. 
morphotypes, with very few coccoid bacteria present. Care must be taken not to misidentify the cellular debris from lysed epithelial cells as coccoid bacteria. The intermediate grade II flora corresponds to a diminished lactobacillary flora, which is mixed with other bacteria. We subdivided this group into two categories, one in which there was still a large amount of lactobacilli present (LBG IIa), and a second group in which the coccoid flora outnumbered the lactobacillary flora (LBG IIb). Finally, the abnormal grade III flora consist of numerous other bacteria, with no lactobacilli present. This grading system was chosen because of its value in clinical practice during pregnancy, ${ }^{57}$ and was extended because former data with three grades comparing Gram stained specimens with wet mounts needed more detailed insights and confirmation. ${ }^{8}$

In the specimens in which lactobacillary morphotypes were seen (LBG I, LBG IIa, and LBG IIb), the morphology of the lactobacilli was recorded (normal, coarse, leptosomic, and mixed types) to allow correction for possible false negative readings. In some cases the short, "coarse" lactobacillary morphotypes might resemble anaerobes such as mobiluncus or Gardnerella vaginalis and might correspond to missed bacterial vaginosis cases.

\section{VAGINAL LACTATE CONCENTRATION}

After the vaginal smears had been taken (see above) and excess cervical mucous removed, vaginal washing with $2 \mathrm{ml}$ physiological saline solution was performed in a standardised manner: the vagina was rinsed and reaspirated three times. Care was taken to flush the left fornix through a 22 gauge needle first; then, after aspiration with the same needle, the right fornix was flushed and the fluid reaspirated. Finally, the vesicovaginal vault was flushed and the fluid reaspirated. All this sampling was performed by the same investigator (GD).

Lactate concentrations were determined by gas liquid chromatography. In 42 patients, the lactate results were not available because the specimen was either not taken (by error), had been lost, or was not processed in an appropriate way. Control tests on 25 samples of vaginal rinsing fluid showed the lactate concentration assay not to be sensitive (results within $2 \%$ ) to delays in testing (two to 24 hours), temperature (up to $35^{\circ} \mathrm{C}$ ), or the presence or absence of cellular debris (centrifugation at $1200 \times g$ for 10 minutes).

\section{BACTERIAL VAGINOSIS}

Bacterial vaginosis was diagnosed according to the Amsel criteria. ${ }^{12}$ Three of the following had to be present: (1) watery, homogeneous vaginal discharge; (2) clue cells; (3) a $\mathrm{pH}$ higher than 4.5 ; and (4) a positive amine test.

\section{STATISTICAL ANALYSIS}

The grades assigned to two slides that had been treated differently could be concordant or discordant. For discordant items, we calculated whether the lactobacillary expression was systematically either overestimated or underestimated after fresh or delayed Gram staining compared with fresh wet mounted vaginal smears. The hypothesis to be tested was that lactobacilli are equally well diagnosed in wet mount preparations as in Gram stained specimens.

Second, we studied whether these findings would still be present when the methods were compared with the functional test: impaired in vivo lactate production by the vaginal lactobacilli.

Either the $\chi^{2}$ or Fisher's test was used for analysis of two by two tables, and the relative risk (RR) with 95\% confidence interval (CI) was calculated to express any significant decrease in lactobacilli in the various groups. In the presence of equal variances among groups, ANOVA and student's $t$ test with the Bonferroni correction were used for comparing the lactate concentrations among LBG groups. In other cases, the non-parametric Welch's equation was used.

\section{Results}

Lactobacillary grades from 646 specimens that had undergone both the wet mount and delayed Gram stain techniques were evaluated. For 238 of these, Gram stains of fresh smears were also available for analysis.

When LBGs assigned to wet mounted specimens were compared with those assigned after Gram staining, concordance rates were higher for abnormal lactobacillary grades than for the normal grade. For LBG III, a $66 \%$ concordance was recorded, for LBG II 54\% (32\% for LBG IIb and $60 \%$ for LBG IIa), and for LBG I concordance was only $12 \%$ (table 1 ). Cases that varied by one grade in either direction were also considered to be concordant ("extended concordance"). Rates of extended concordance were again higher for the abnormal grades: $91 \%$ for LBG III, $95 \%$ for LBG II ( $100 \%$ for LBG IIb and $93 \%$ for LBG IIa), and only $77 \%$ for LBG I (table 1 ).

The increased likelihood of a more abnormal LBG being assigned after Gram staining than after wet mounting (RR, $4.2 ; 95 \% \mathrm{CI}, 3.3$ to 5.2) remained present after exclusion of the patients with bacterial vaginosis (RR, 5.6; 95\% CL, 4.3 to 7.3 ) and those with an abnormally

Table 1 Assessment of lactobacillary grades in wet mounts and in Gram stained, transported specimens

\begin{tabular}{llllll}
\hline \multirow{2}{*}{$\begin{array}{l}\text { Delayed Gram } \\
\text { stain }\end{array}$} & \multicolumn{3}{l}{ Fresh wet mount } & \\
\cline { 2 - 5 } & I & IIa & IIb & III & All \\
\hline I & $\mathbf{3 4}$ & 19 & 0 & 1 & 54 \\
IIa & 176 & $\mathbf{1 1 8}$ & 18 & 10 & 317 \\
IIb & 56 & 46 & $\mathbf{1 9}$ & 29 & 150 \\
III & 12 & 13 & 22 & $\mathbf{7 8}$ & 125 \\
All & 273 & 196 & 59 & 118 & 646 \\
\hline
\end{tabular}

Bold figures represent "fully concordant" numbers. Numbers in regular print represent "extreme discordance": the grade of lactobacillary flora given by one technique differs radically from the grade allocated by the other technique. Numbers in italic represent "limited concordance": the grade given by one technique differs by only one level from the grade given by the other technique. Finally, the sum of the figures in bold and in italic combined represent "extended concordance": the grade allocated by one technique differs maximally one level from, or is equal to, the grade allocated by the other technique. It can easily be deduced from this table that the Gram stain has a tendency to produce higher lactobacillary grades (less healthy flora) than those seen on fresh wet mounts. 
Table 2 Concordance and discordance rates comparing wet mount with Gram stained specimens (A) after transport of the specimen in Stuart's medium $(n=646)$ and $(B)$ in a subgroup comparing wet mount with fresh Gram stain $(n=238)$ in patients with or without bacterial vaginosis

\begin{tabular}{|c|c|c|c|c|c|}
\hline & \multirow[b]{2}{*}{ Number } & \multirow[b]{2}{*}{$\begin{array}{l}\text { Concordant } \\
\text { (\% of total) }\end{array}$} & \multicolumn{3}{|l|}{ Discordant } \\
\hline & & & $\begin{array}{l}\text { Lower } L B G \\
\text { on Gram } \\
\text { (\% of total) }\end{array}$ & $\begin{array}{l}\text { Higher LBG } \\
\text { on Gram } \\
\text { (\% of total) }\end{array}$ & $\begin{array}{l}\text { Relative risk of } \\
\text { higher } L B G \text { in Gram } \\
(95 \%(C L)\end{array}$ \\
\hline \multicolumn{6}{|c|}{ (A) Wet mount compared with delayed Gram stained specimen } \\
\hline All & 646 & $249(39 \%)$ & $77(12 \%)$ & $325(50 \%)$ & $4.2(3.3 \text { to } 5.2)^{\star \star}$ \\
\hline Extended concordance & 646 & $559(87 \%)$ & $11(2.0 \%)$ & $81(13 \%)$ & $7.4(4.0 \text { to } 14)^{\star \star}$ \\
\hline Women with BV excluded & 575 & $211(37 \%)$ & $55(10 \%)$ & $309(54 \%)$ & $5.6(4.3 \text { to } 7.3)^{\star \star}$ \\
\hline Coarse-type LB excluded & 472 & $162(34 \%)$ & $68(14 \%)$ & $242(51 \%)$ & $3.6(2.8 \text { to } 4.5)^{\star \star}$ \\
\hline \multicolumn{6}{|c|}{ (B) Wet mount compared with fresh Gram stained specimen } \\
\hline All & 238 & $103(43 \%)$ & $35(15 \%)$ & $100(42 \%)$ & $2.9(2.0 \text { to } 4.0)^{\star \star}$ \\
\hline Extended concordance & 238 & $217(91 \%)$ & $7(3 \%)$ & $14(6 \%)$ & $2.0(0.8$ to 4.9$)$ \\
\hline Women with BV excluded & 219 & $91(42 \%)$ & $28(13 \%)$ & $100(46 \%)$ & $3.6(2.5 \text { to } 5.2)^{\star \star}$ \\
\hline Coarse-type LB excluded & 183 & $86(47 \%)$ & $27(15 \%)$ & $70(38 \%)$ & $2.5(1.7 \text { to } 3.8)^{\star}$ \\
\hline
\end{tabular}

"Extended concordance": the grade allocated by one technique differs maximally one level from, or is equal to, the grade allocated by the other technique.

${ }^{\star} \mathrm{p}<0.01 ;{ }^{\star \star} \mathrm{p}<0.0001$ ( $\chi^{2}$ test $)$

$\mathrm{BV}$, bacterial vaginosis; CL, confidence limits; LB, lactobacillary morphotype; LBG, lactobacillary grades.

coarse type of lactobacilli present ( $R R, 3.6$; $95 \%$ CI, 2.8 to 4.5 ) (table 2). The same significant relations were found when the results from freshly Gram stained specimens were compared with wet mounts (table 2), but the relative risk of having a higher LBG was two times lower. Under the extended concordance criterion, the difference between fresh Gram stains and wet mounts was not significant (RR, 2.0; 95\% CI, 0.8 to 4.9 ).

To investigate whether the discordance stemmed from false positive LBG readings on Gram stained specimens or from false negative readings on wet mount specimens, we compared LBG with lactate production by vaginal lactobacilli. Table 3 shows the mean lactate concentration $(\mathrm{mg} / \mathrm{ml})$ in vaginal washing fluid in the various LBG groups. In the wet mount group there was a clear progressive decrease in lactate concentration with increasing LBG (ANOVA: $\mathrm{F}=30.5 ; \mathrm{p}<0.00001$ ). The gradual decline is significant between each of the groups. After Gram staining the decline was less pronounced (ANOVA: $\mathrm{F}=28.8$; $\mathrm{p}<0.0001$ ) and less regular (no significant decline between LBG I and LBG IIa, and between LBG IIb and III).

Thus, whereas a smooth gradual decline of lactate concentration with increasing LBG is noted in wet mounts, an abrupt biphasic pattern seems to be present in Gram stained specimens (cutting edge between LBG IIa and LBG IIb); that is, the correlation between vaginal lactate concentration and lactobacillary grading was better for wet mounted specimens than for Gram stained samples. Gram stains classified 253 women into this abnormal group

Table 3 Lactobacillary grades (LBG) on wet mount and delayed Gram stain versus vaginal lactate concentration ( $\mathrm{mg} / \mathrm{ml}$ rinsing fluid)

\begin{tabular}{|c|c|c|c|c|c|c|}
\hline \multirow[b]{2}{*}{$L B G$} & \multicolumn{3}{|c|}{ Wet mount } & \multicolumn{3}{|c|}{ Delayed Gram stain } \\
\hline & $N$ & $\begin{array}{l}\text { Mean lactate } \\
\mathrm{mg} / \mathrm{ml}(S D)\end{array}$ & $p$ Value & $N$ & $\begin{array}{l}\text { Mean lactate } \\
m g / m l(S D)\end{array}$ & $p$ Value \\
\hline I & 259 & $1.70(148)$ & \multirow[b]{2}{*}{0.029} & 49 & $1.86(144)$ & \multirow[b]{2}{*}{ NS } \\
\hline $\mathrm{IIa}$ & 192 & $1.54(130)$ & & 310 & $1.72(144)$ & \\
\hline & & & \multirow{3}{*}{$\begin{array}{l}<0.0001 \\
0.0003\end{array}$} & & & \multirow{3}{*}{$\begin{array}{l}<0.0001 \\
<0.02\end{array}$} \\
\hline IIb & 56 & $0.78(54)$ & & 140 & $0.96(94)$ & \\
\hline III & 105 & $0.46(51)$ & & 113 & $0.73(60)$ & \\
\hline
\end{tabular}

NS, not significant.
(LBG IIb-III), with a mean lactate concentration of $89 \mathrm{mg} / \mathrm{ml}$, whereas wet mounts classified 161 women into this group, with a mean lactate concentration of $56 \mathrm{mg} / \mathrm{ml}(\mathrm{p}<0.005)$. This indicates a false positive rate of $24 \%$ by Gram staining.

As discussed in an earlier report, lactate concentrations $(<10 \mathrm{mg} / \mathrm{ml})$, indicating severe depression of lactobacillary function, are better predicted by LBG III in wet mount (sensitivity $70 \%$, specificity 90\%) than in Gram stained specimens (sensitivity $55 \%$, specificity $86 \%$ ). ${ }^{15}$ Negative predictive values were similar $(95 \%$ and $98 \%$, respectively), but positive predictive values, the true prediction of low lactate by LBG III, were also higher for wet mount $(21 \%)$ than for Gram stained specimens (13\%).

\section{Discussion}

Simple microscopic assessment of the vaginal microflora can provide much information about a woman's risk of having vaginitis, cervicitis, and of developing ascending infection and pregnancy complications such as intrauterine infection, midtrimester abortion, premature labour, and premature rupture of the membranes. ${ }^{5-7} 1617$

Being an essential part of various scoring systems expressing vaginal disturbance of the microflora in general, ${ }^{18}$ and bacterial vaginosis in particular, ${ }^{19}$ the grading of lactobacillary morphotypes into normal, intermediate, and abnormal flora ${ }^{2}$ is crucial. As a first approach, lactobacillary grading might even be used as a stand alone test to guide further microbiological investigation.

By using LBG as a prescreening test, some authors found an association between disturbed LBG during the first pregnancy visit and pregnancy outcome..$^{520}$ However, in the interpretation of these studies one must keep in mind a certain number of pitfalls. First, the finding of severely depressed lactobacillary morphotypes in a woman's vagina does not necessarily mean that she has bacterial vaginosis. ${ }^{13}$

Although everyone agrees that most women expressing bacterial vaginosis, a clinical condition combining all or some of the bacterial vaginosis criteria (high $\mathrm{pH}$, clue cells, fishy smelling discharge, and anaerobic overgrowth 
by $G$ vaginalis, Mobiluncus spp, Prevotella spp, Bacteroides spp, and others), also lack normal appearing lactobacilli, care should be taken not to equate the finding of disturbed lactobacillary flora with the diagnosis of bacterial vaginosis.

Our study shows that, even after exclusion of those cases with a clinical diagnosis of bacterial vaginosis, a number of women have severely reduced numbers of lactobacilli. Therefore, these women must have other conditions causing the vaginal lactobacilli to disappear. In previous work we have shown that $N$ gonorrhoeae, $C$ trachomatis, $T$ vaginalis, and syphilis are very often associated with LBG III (severely depressed lactobacilli). ${ }^{56}$

In more recent work, aerobes of intestinal origin, such as group B streptococci, Gram negative rods (Escherichia coli, Klebsiella spp, and Acinetobacter $s P P$ ) and actinomyces, were often found to be associated with LBG IIb and LBG III, ${ }^{20-22}$ partly analogous to the condition "desquamative vaginitis", formerly described by Gardner, ${ }^{4}$ and reintroduced by Sobel. ${ }^{23}$ We propose the term "aerobic vaginitis" for this condition, because it causes severe inflammation both clinically (red vagina, yellow foul smelling discharge) and microscopically (LBG IIb-III, numerous toxic, non-agglutinated leucocytes, and increased parabasal epitheliocytes).

A second pitfall in the studies describing the influence of depressed LB flora on the outcome of pregnancy is the lack of a standardised test for grading the lactobacilli. From the clinical point of view, wet mounting would be very desirable, because it enables immediate diagnostic and prophylactic measures to be taken, which encourages closer follow up. ${ }^{16}$ The use of Gram stained specimens for grading vaginal lactobacilli is a direct consequence of the growing interest in bacterial vaginosis, the diagnosis of which was first based and defined on Gram stained smears. ${ }^{9}$ This choice may be the result of local habits in routine medicine, where laboratory based results gain more confidence than ill practiced wet mount microscopy. Furthermore, Gram stains can be kept for a limited time and be re-examined if necessary, a feature that until recently was not thought to be possible in wet mounts. ${ }^{11}$

In a previous study we noted great differences in LBG diagnosis according to the method used. ${ }^{8}$ In general, Gram staining revealed fewer lactobacilli than did wet mounting, especially after three to six hours of transport in Stuart's medium. We postulated a loss of lactobacilli by the process of Gram stain preparation, and a selection towards nonlactobacillary microorganisms by the use of transport medium. However, the lack of a gold standard prevented us from deciding which method of preparation (Gram stain or wet mount) was preferable.

In our present study, vaginal lactate concentration was chosen as the standard because of its functional character. Lactobacilli are unique in their ability to convert glycogen to lactate, ${ }^{13}$ and there is no evidence to suggest that this production is greatly influenced by the presence or absence of other bacteria. Other possi- ble standards, which were considered but eliminated, were culture of lactobacilli and $\mathrm{H}_{2} \mathrm{O}_{2}$ production.

Culture was considered to be an inaccurate test because only limited numbers of the lactobacillary strains in the vagina will grow in Rogosa medium. Even semiquantitative growth would not reflect the situation in vivo. ${ }^{24}$ $\mathrm{H}_{2} \mathrm{O}_{2}$ production has been recognised as a marker of efficient microbial defence against bacterial vaginosis ${ }^{15}$ but, unlike lactate production, it is not known whether all functional lactobacilli express this peroxidase system.

When we looked at the correlations of LBGs of specimens prepared as both wet mounts and Gram stains with lactate concentrations in standardised vaginal washes, we noted a sharper correlation of vaginal lactate concentration with wet mount than with Gram stain grades. In addition, very low lactate concentrations were better predicted by the wet mount technique. Of the samples considered normal by wet mounting (LBG I and LBG IIa), 24\% were graded abnormal (LBG IIb and LBG III) after Gram staining. It would, however, be interesting to measure peroxidase activity in future studies, comparing LBGs in different settings.

We conclude that wet mounting is more accurate than Gram staining for the assessment of lactobacillary morphotypes. Furthermore, wet mount microscopy is cheaper, easier to perform, and allows immediate prophylactic and therapeutic action. To optimise screening in women, especially during pregnancy, intense efforts to instruct trainees and physicians to (re)gain standard knowledge of wet mount microscopy are needed urgently.

1 Döderlein A. Das Scheidensekret und seine Bedeutung für das Puerperalfieber. Leipzig: Verlag van Eduard Besold, 1892.

2 Schröder K. Zur pathogenese und Klinik des vaginalen Vaginalbiocoenose uaf sechs grundbilder. Zentralbl Gynakol 1921;45:1350-61.

3 Gardner HL, Dukes CD. Haemophilus vaginalis vaginitis. A newly defined specific infection previously classified "nonspecific" vaginitis. Am f Obstet Gynecol 1955;69:962-76.

4 Gardner HL. Desquamative inflammatory vaginitis: a newly defined entity. Am f Obstet Gynecol 1968;102:1102-5.

5 Donders GGG, De Wet GH, Hooft P, et al. Lactobacilli in Papanicolaou smears, genital infections and pregnancy. $\mathrm{Am}$ f Perinatol 1993;10:358-61

6 Donders GGG, Moerman P, De Wet GH, et al. The association between chlamydia cervicitis, chorioamnionitis and neonatal complications. Arch Gynecol Obstet 1991;249:7985.

7 Hay PE, Lamont RF, Taylor-Robinson, et al. Abnormal bacterial colonisation of the genital tract and subsequent preterm delivery and late miscarriage. BMf 1994;308:295-8. of vaginal lactobacillary flora in wet mount and fresh or delayed Gram stain. Infect Dis Obstet Gynecol 1996;4:2-6.

9 Spiegel CA, Amsel R, Homes KK. Diagnosis of bacterial vaginosis by direct Gram stain of vaginal fluid. F Clin Microbiol 1983;18:170-7.

10 Platz-Christensen JJ, Larsson P-G, Sundström E, et al. Detection of bacterial vaginosis in wet mount, PapanicoDetection of bacterial vaginosis in wet mount, Papanico-
laou stained vaginal smears and in Gram stained smears. Acta Obstet Gynecol Scand 1995;74:67-70.

11 Larsson P-G, Platz-Christensen JJ. Enumeration of clue cells in rehydrated air-dried vaginal wet smears for the diagnosis of bacterial vaginosis. Obstet Gynecol 1990;76: 727-30

12 Amsel R, Totten PA, Spiegel CA, et al. Nonspecific vaginitis. Diagnostic criteria and microbial and epidemiological associations. Am f Med 1983;74:14-22.

13 Cruickskank R, Sharman A. The biology of the vagina in the human subject II. The bacterial flora and secretion of the vagina in relation to glycogen in the vaginal epithelium. $\mathcal{F}$
Obstet Gynecol Br Emp 1939;208:208-12.

14 Eschenbach DA, Davick PR, Williams BL, et al. Prevalence of hydrogen peroxide-producing lactobacillus species in normal women with bacterial vaginosis. 7 Clin Microbiol 1989;27:251-6.

15 Donders GGG, Desmyter J, Vereecken A. Vaginitis [letter]. N Engl F Med 1998;338:1548. 
16 Martius J, Krohn MA, Hillier SL, et al. Relationships of vaginal lactobacillus species, cervical chlamydia trachomatis and bacterial vaginosis to preterm birth. Obstet Gyneco

17 Krohn MA, Hillier SL, Nugent RP, et al. The genital flora of women with intraamniotic infection. Vaginal infection and prematurity study group. F Infect Dis 1955;171: 1475-80.

18 Hillier SL, Krohn MA, Nugent RP, et al. Characteristics of three vaginal flora patterns assessed by Gram stain among pregnant women. Vaginal infections and prematurity study group. Am f Obstet Gynecol 1992;166:938-44.

19 Nugent RP, Krohn MA, Hillier SL. Reliability of diagnosing bacterial vaginosis is improved by a standardised method of Gram stain interpretation. F Clin Microbiol 1991;29:297-301.
20 Donders GGG, Odds A, Vereecken A, et al. Abnormal vaginal flora, but not full blown bacterial vaginosis in first trimester is associated with preterm birth. Prenat Neonat Med 1998;3:588-93.

21 Donders GGG. Bacterial vaginosis during pregnancy: screen and treat [editorial]. Eur $\mathcal{F}$ Obstet Gynecol Reprod Biol 1999;83:1-4.

22 Donders GGG Microscopy of the bacterial flora on fresh vaginal smears. Infect Dis Obstet Gynecol 1999;7:126-7.

23 Sobel JD. Desquamative inflammatory vaginitis: a new subgroup of purulent vaginitis responsive to topical $2 \%$ clindamycin therapy. Am f Obstet Gynecol 1994;171:1215-20.

24 Rogosa M, Shape ME. Species differentiation of human lactobacilli. F Gen Microbiol 1960;23:197-201.

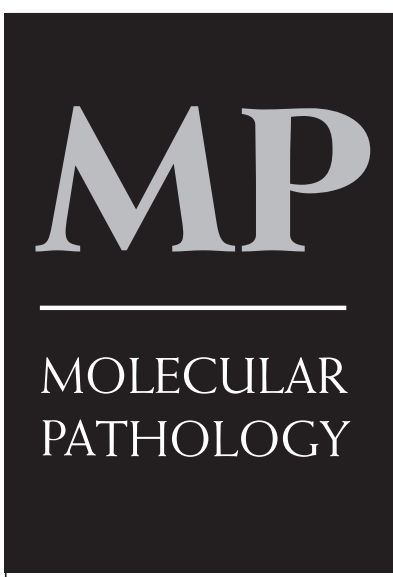

\section{Contents}

\section{February 2000 Vol 53 No 1}

\section{Reviews}

1 Demystified ... Transcription W M Macfarlane

$8 x$ Ray crystallography $M S$ Smyth, $\mathcal{J} H \mathcal{F}$ Martin

\section{Papers}

15 Relation of Bcl-2 expression to androgen receptor, $\mathrm{p} 21 \mathrm{WAF} 1 / \mathrm{CIP} 1$, and cyclin D1 status in prostate cancer $Z$ Kolár̆, P G Murray, K Scott, A Harrison, B Vojtěšek, f Dušek

19 Amplification of PCR products in excess of 600 base pairs using DNA extracted from decalcified, paraffin wax embedded bone marrow trephine biopsies $C L$ Wickham, $M$ Boyce, $M$ V Foyner, P Sarsfield, B $S$ Wilkins, D B fones, $S$ Ellard

24 p53 and K-ras gene mutations in carcinoma of the rectum among Finnish women K Servomaa, A Kiuru, V-M Kosma, P Hirvikoski, T Rytömaa

31 Expression of an LDL receptor allele with two different mutations (E256K and I402T) U Ekström, M Abrahamson, T Svegar, X-M Sun, A K Soutar, P Nilsson-Ehle

37 Epstein-Barr virus (EBV) in infectious mononucleosis: detection of the virus in tonsillar B lymphocytes but not in desquamated oropharyngeal epithelial cells $G$ Niedobitek, A Agathanggelou, N Steven, L S Young

43 Localisation of HHV-8 in AIDS related lymphadenopathy $\mathcal{F} \mathcal{F}$ O'Leary, $M$ Kennedy, K Luttich, V Uhlmann, I Silva, $\mathcal{F}$ Russell, O Sheils, $M$ Ring, $M$ Sweeney, $C$ Kenny, $N$ Bermingham, $C$ Martin, $M$ O'Donovan, D Howells, S Picton, $S$ B Lucas

\section{Technical report}

48 Improved in situ detection method for telomeric tandem repeats in metaphase spreads and interphase nuclei $V$ Uhlmann, $M$ Prasad, I Silva, K Luttich, L Grande, L Alonso, M Thisted, KF Pluzek, f Gorst, M Ring, M Sweeney, C Kenny, $C$ Martin, $\mathcal{F}$ Russell, $N$ Bermingham, $M$ O'Donovan, O Sheils, f f O'Leary

\section{Short report}

51 Direct multiplex amplification of DNA from a formalin fixed, paraffin wax embedded tissue section L Cawkwell, P Quirke

\section{Miscellanea}

53 Book review - Instructions for authors 